\title{
ANALISIS SWOT PT SUMO ADVERTISING
}

Didi mulyadi ${ }^{1}$

Universitas Sahid, Jakarta

\begin{abstract}
Abstrak
Tujuan penelitian ini adalah untuk menemukan analisis SWOT yang tepat untuk PT SUMO ADVERTISING dalam meghadapi persaingan perusahaan secara produk dan kemampuan perusahaan dalam menejemen internal. Metode dasar yang digunakan dalam penelitian ini adalah metode deskriptif analitik. Teknik pelaksanaannya menggunakan metode survey. Hasil penelitian adalah Kondisi internal PT. SUMO Advertising adalah memiliki kekuatan dalam hal kepercayaan klien juga budaya perusahaan yang kuat menghasilkan kapasitas perusahaan yang sebenarnya bisa terus bersaing di industri selain media luar ruang. Kondisi eksternal PT. Pariwara Advertising berupa ancaman yang paling kuat untuk perusahaan adalah regulasi pemerintah daerah DKI Jakarta.
\end{abstract}

Kata-kata Kunci: SWOT. Deskriptif. Advertising

\begin{abstract}
The purpose of this study was to find the right SWOT analysis for PT SUMO ADVERTISING in facing company competition in terms of products and the company's ability in internal management. The basic method used in this research is descriptive analytic method. The implementation technique uses a survey method. The result of this research is the internal condition of PT. SUMO Advertising is having strength in terms of client trust as well as a strong corporate culture resulting in a company capacity that can actually continue to compete in industries other than outdoor media. The external condition of PT. Pariwara Advertising in the form of the most powerful threat to companies is the regulation of the DKI Jakarta local government.
\end{abstract}

Keyword: SWOT. Deskriptif. Advertising

\section{PENDAHULUAN}

Analisis Lingkungan Internal Analisis lingkungan internal bertujuan untuk mengidentikasi dan menganalisis faktor strategis internal yang Memengaruhi keberlangsungan bisnis PT. SUMO Advertising. Faktor strategis internal terdiri dari kekuatan dan kelemahan. Kekuatan merupakan faktor strategis internal yang dapat dioptimalkan untuk meningkatkan daya saing PT. SUMO Advertising sedangkan kelemahan merupakan faktor strategis internal yang harus diperbaiki oleh perusahaan dalam merumuskan faktor penentu kesuksesn PT. SUMO Advertising. Hasil wawancara kepada repsonden internal didapatlah 5 kekuatan dan 5 kelemahan.

Melalui hubungan variabel marketing mix terhadap line extension, dapat dilakukan analisa SWOT untuk di implementasikan strategi line extension. Implementasi startegi berdampak dalam memperkuat merek serta memperluas segmen baru melalui melalui produk yang diciptakannya yaitu produk yang memiliki variasi warna dan dimensi sesuai persepsi konsumen (Nugraha et al., 2016).

Matrik SWOT disusun untuk menggambarkan bagaimana peluang dan ancaman eksternal yang dihadapi perusahaan dapat disesuaikan dengan kekuatan dan kelemahan yang dimiliki perusahaan (Munadi, 2008). Analisis SWOT telah menjadi salah satu alat yang berguna dalam dunia bisnis. Metode ini merupakan sebuah analisa yang cukup baik, efektif dan efisien serta sebagai alat yang cepat dan tepat dalam menemukan dan mengenali 
kemungkinan-kemungkinan yang berkaitan de- ngan inovasi baru dalam dunia bisnis (Noor, 2014).

Analisis SWOT merupakan instrumen yang bermanfaat dalam melakukan analisis strategi, dalam konteks artikel ini ditujukan untuk menilai kualitas layanan perbankan, sehingga diharapakan mampu meminimalisasi kelemahan yang terdapat dalam suatu lembaga perbankan serta menekan dampak ancaman yang timbul dan harus dihadapi (Adhitya Wulanata Chrismastianto, 2017). Model analisis yang paling banyak dipakai oleh perusahaan saat ini baik untuk menganalisis perencanaan secara internal maupun eksternal adalah analisis SWOT (Putong, 2003).

Tujuan penelitian ini adalah untuk menemukan analisis SWOT yang tepat untuk PT SUMO ADVERTISING dalam meghadapi persaingan perusahaan secara produk dan kemampuan perusahaan dalam menejemen internal.

\section{METODE}

Metode dasar yang digunakan dalam penelitian ini adalah metode deskriptif analitik. Teknik pelaksanaannya menggunakan metode survey(Handayani \& Nurlaila, 2017). Data yang digunakan dalam adalah data primer dan sekunder. Data primer dikumpulkan dengan metode survei, observasi dan wawancara langsung di lapangan (Dokman Marulitua Situmorang, Erlina, 2018). Pendekatan kualitatif dengan analisis SWOT dipilih untuk menggali data serta merumuskan konsep pengembangan (Hermawan, 2017). Model SWOT yang digunakan adalah model yang biasanya digunakan untuk penelitian perumusan strategi (Tamara, 2016).

\section{HASIL DAN PEMBAHASAN}

\section{Kekuatan (Strength)}

Kekuatan perusahaan merupakan faktor internal yang harus dikembangkan untuk mendukung strategi perusahaan. Kekuatan perusahaan terbentuk diantaranya dari pengalaman puluhan tahun dan jaringan bisnis yang luas sehingga PT. SUMO Advertising terus eksis hingga saat ini. Faktor strategis internal yang digolongkan sebagai kekuatan PT. SUMO Advertising adalah 1) berpengalaman 38 Tahun di industri media luar ruang Jakarta. PT. SUMO Advertising mulai menjalankan bisnisnya pada tahun 1978. Pengalaman selama puluhan tahun menjadikan PT. SUMO Advertising lebih unggul dalam jaringan bisnis di industri media luar ruang DKI Jakarta.

1. Harga produk bersaing. Untuk menentukan standar harga produk pada media luar ruang, PT. Pariwara Advertising akan dibandingkan dengan PT. Lestari Cipta Mandiri yaitu perusahaan media luar ruang yang juga telah berdiri selama 20 tahun. Dapat dilihat pada Tabel 2, bahwa SUMO memiliki harga jual produk yang lebih rendah dibandingkan perusahaan pembanding yaitu PT. Lestari Cipta Mandiri.

ProdukPariwara LCM

Billboard (Rp) 799.000.000 813.000000

LED (Rp) 1.521.000.000 1.613.466.667

2. Kepercayaan klien besar. Pariwara memiliki beberapa klien yang sama dari tahun 2012 sampai dengan 2021. Diantaranya adalah Bank CIMB dan Bank BNI. Dari hasil wawancara dengan klien tersebut, diperoleh kesimpulan bahwa alasan untuk terus menggunakan jasa SUMO adalah karena Pariwara sangat menjaga kualitas produknya.

3. Budaya perusahaan kuat. Budaya belajar di PT. SUMO Advertising menjadikan loyalitas terhadap perusahaan tertanam kuat. Selain itu, nilai-nilai integritas dijunjung tinggi dan menjadi ukuran dalam menilai kemauan setiap karyawan SUMO.

4. Memiliki titik iklan strategis di DKI Jakarta. Berbeda dengan beberapa perusahaan media luar ruang lainnya, SUMO memiliki 44 titik iklan yang disewa atau dibeli oleh SUMO. Berbeda dengan PT. Lestari Cipta Mandiri yang hanya memiliki lima titik iklan sehingga ketika menjual titik iklan, harga yang ditawarkan lebih tinggi 


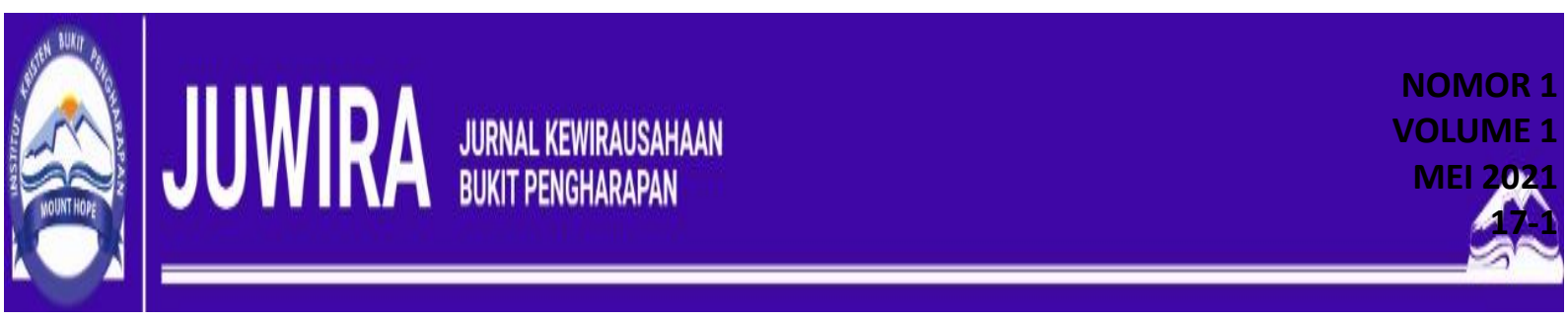

dibandingkan SUMO karena titik tersebut dimiliki oleh pihak lain, dan LCM hanya sebagai perantara

\section{Kelemahan (Weakness)}

Setiap perusahaan tumbuh tidak hanya membawa kesuksesan yang dapat diukur melalui jumlah proft yang dihasilkan. Pertumbuhan tersebut, lahir dari tantangan bisnis yang mampu dihadapi oleh perusahaan dan salah satu dari tantangan bisnis itu adalah kelemahan yang masih dimiliki perusahaan sehingga berdampak kepada kemajuan perusahaan. Faktor strategis internal yang digolongkan sebagai kelemahan PT. SUMO Advertising adalah

1. Produk didonimasi oleh billboard. Sebanyak 80\% produk PT. SUMO Advertising didominasi oleh Billboard. Tidak dengan LCM, yang memiliki produk iklan televisi di TVRI sehingga memiliki sumber pemasukan lain selain Billboard.

2. Tingginya turn over karyawan. Pada Tabel 3 terlihat bahwa selama kurun waktu 2019-2020, PT. SUMO Advertising mengalami pergantian staf dengan jumlah cukup signifkan yaitu sebesar sembilan orang. Penurunan jumlah SDM ini disebabkan kondisi perusahaan.

3. Belum adanya edukasi terhadap klien.Saat ini belum ada tolak ukur yang jelas dalam media luar ruang apakah iklan tersebut tepat sasaran dan berdampak bagi produk karena dengan posisi media luar ruang di ruang publik seperti jalan, kita tidak bisa menganalisis siapa saja yang tertarik atau bahkan sama sekali tidak melihat iklan di billboard tersebut.

4. Menurunnya penjualan. Penjualan PT. SUMO Advertising yang terus menurun sampai dengan Rp5 Milyar pada tahun 2015, menyebabkan kondisi operasional perusahaan terganggu. Penurunan penjualan juga dialami oleh PT. Lestari Cipta Mandiri, ketika tahun 2012 memiliki jumlah penjualan sebesar Rp29 Milyar, turun pada tahun 2013 menjadi Rp18 Milyar dan turun menjadi 11 Milyar pada tahun 2014. Namun, berbeda dengan Pariwara, LCM melakukan perluasan produk dengan menjangkau produk iklan TV sehingga penjualan pada tahun 2015 dapat kembali naik menjadi Rp17 Milyar.

5. Belum ada divisi riset yang mengukur keandalan produk. Dalam industri media luar ruang dimana produk yang diunggulkan adalah billboard, membuat para pelaku bisnis sulit untuk mengembangkan pangsa pasar karena kompetisi yang sengit.

\section{Analisis Faktor Strategis Eksternal}

Analisis lingkungan eksternal bertujuan untuk mengidentikasi dan menganalisis faktor strategis eksternal yang memengaruhi keberlangsungan PT. SUMO Advertising di industri media luar ruang di Indonesia. Hasil penelitian menunjukan bahwa terdapat delapan faktor strategis eksternal yang terdiri dari empat peluang dan empat ancaman.

1. Peluang (Opportunity)

Peluang adalah situasi penting yang mengguntungkan dalam lingkungan perusahaan. Contohnya adalah perubahan teknologi dan meningkatnya hubungan antara perusahaan dengan pembeli atau pemasok merupakan gambaran peluang bagi perusahaan.Faktor strategis eksternal yang digolongkan sebagai peluang yang dapat dimanfaatkan dalam keberlangsungan bisnis PT. Pariwara Advertising yaitu 1) Potensi produk baru (LED, TV dan media sosial). Pertumbuhan belanja iklan lainnya di tahun 2019, lebih didorong oleh pergerakan yang positif di TV yaitu secara total meningkat sebesar 12\%. Tahun 2020, pertumbuhan iklan mobile digital meningkat tiga kali lipat, atau sekitar $15,5 \%$ dari total belanja iklan digital di Indonesia. Meskipun meningkat, jumlah itu hanya 1,1\% dari total 
belanja iklan media saat ini. Artinya, belanja iklan media digital masih amat minim. Pada akhir tahun 2021, mayoritas belanja iklan digital akan dialokasikan ke arah mobile. Hal inilah yang belum dipersiapkan oleh SUMO.

Mobilitas masyarakat semakin tinggi. Menurut penelitian yang dilakukan oleh Smarter (2015) dengan total 310 responden. Hampir seluruh responden melakukan perjalanan ke tengah kota Jakarta, Separuh responden melakukan perjalanan menuju selatan Jakarta, dengan jalan yang paling banyak dilalui adalah TB Simatupang, Pasar Minggu, dan daerah Kuningan.

Pertumbuhan belanja iklan. Menurut laporan Nielsen Advertising Information Services , pertumbuhan belanja iklan DKI Jakarta di akhir tahun 2015 bergerak positif. Jika dilihat dari jenis medianya, pertumbuhan belanja iklan di tahun 2015, lebih didorong oleh pergerakan yang positif di TV yaitu secara total meningkat sebesar $12 \%$. Pertumbuhan belanja iklan koran di kuartal empat tahun 2015 menunjukkan pergerakan yang positif, yaitu tumbuh sebesar $1 \%$. Walaupun angka pertumbuhan tahunan masih menurun sebesar $4 \%$, tercatat kecenderungannya sudah membaik dibandingkan kuartal-kuartal sebelumnya. Total belanja iklan koran di akhir tahun 2015 mencapai Rp30,8 triliun.

Perkembangan Teknologi Informasi. Media luar ruang sangat berpotensi untuk semakin menjual jika bisa terkoneksi dengan aktivitas masyarakat DKI Jakarta di dunia digital. Bila dilihat dari wilayah domisilinya, 78,5\% dari total Rp88,1 juta pengguna internet di Indonesia tinggal di wilayah Indonesia bagian barat. Ibukota DKI Jakarta menjadi wilayah dengan penetrasi paling tinggi dengan $65 \%$ pengguna internet.

2. Ancaman (Threats)

Ancaman adalah situasi penting yang tidak menguntungan dalam lingkungan perusahaan. Ancaman merupakan pengganggu utama bagi posisi sekarang atau yang diinginkan perusahaan. Salah satu ancaman yang sedang dihadapi oleh PT. SUMO Advertising adalah adanya peraturan- peraturan pemerintah yang tidal bersinergi dengan bisnis media luar ruang di DKI Jakarta. Faktor strategis eksternal yang digolongkan sebagai ancaman yang dapat dimanfaatkan dalam keberlangsungan bisnis PT. SUMO Advertising, yaitu Regulasi Pemerintah Daerah. Dalam industri media luar ruang, sangat erat dengan regulasi yang ada di pemerintah daerah. setiap Perda atau Pergub yang terbit akan berdampak signifikan terhadap internal perusahaan. Sebagai contoh, pada awal tahun 2015, terbit Pergub terbaru No. 1 Tahun 2015, tentang "Larangan Penyelenggaran Reklame Rokok dan Produk Tembakau Pada Media Luar Ruang", yang melarang reklame rokok dan produk tembakau pada media luar ruang di seluruh wilayah Provinsi Daerah Khusus Ibukota Jakarta.

Estetika Kota, Menurut Gubernur DKI Jakarta, Basuki Tjahaja Purnama (Ahok), keberadaan reklame di Jakarta begitu banyak dan tak terkendali. Ironisnya, selain menutupi estetika gedung dan membahayakan ketika musim hujan, tidak sedikit pemilik reklame yang tidak membayar pajak. Oleh karena itu, setelah proyek Mass Rapid Transit (MRT) rampung pada 2018, seluruh reklame di Jakarta harus berbentuk dengan LED. Peraturan ini dibuat agar estetika kota terjaga dan media luar ruang dapat menyatu dengan kota.

Industri Media lain (TV), Nielsen Advertising Information Services mencatat, dari total belanja iklan pada semester I/2015, jatah iklan paling banyak didapat oleh media televisi sekitar Rp41,03 triliun atau 71,7\%. Pertumbuhan ini meningkat 9\% dibandingkan dengan tahun 2014. Hal ini mengindikan bahwa, persaingan media luar ruang bukan hanya terjadi di sesama pelaku media luar ruang. banyaknya ragam media iklan, membuat media luar ruang mulai kehilangan pamornya. Jika di TV, informasi dan kreativitas lebih menarik untuk di nikmati maka media luar ruang harus memberikan nilai baru untuk pengguna iklan agar bisa bersaing dengan media iklan TV.

Daya Beli Klien. Iklan rokok menjadi nomer satu penyumbang terbesar kosongnya sejumlah media iklan luar ruangan seperti billboard dan baliho di beberapa sudut Jakarta. Sekitar 30\% dari 1700-an titik media iklan outdoor saat ini kosong, sebagian besar karena larangan iklan rokok di tempat umum. Dari jumlah media outdoor yang kosong tersebut, 


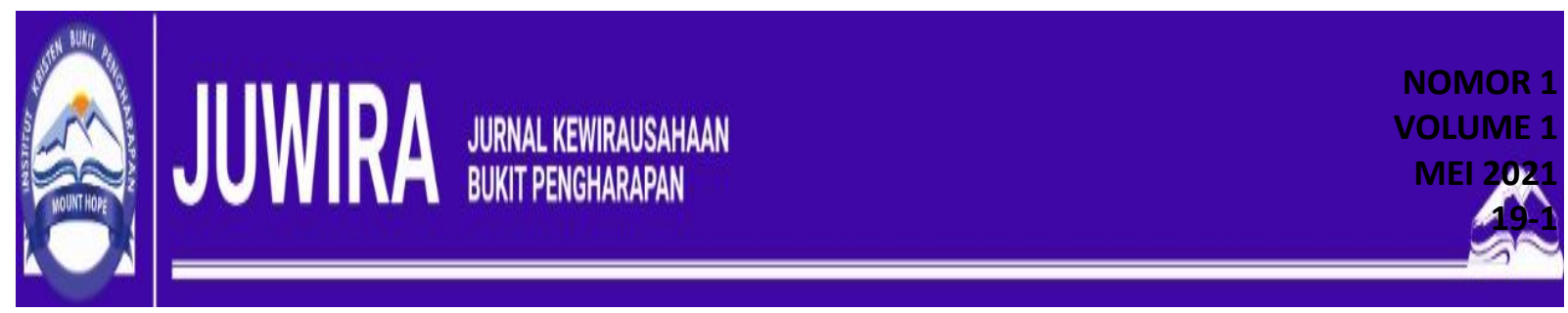

penurunan rokok menjadi penyumbang terbesar yakni 14,4\%, diikuti real estate $12,59 \%$, perbankan 5,04\%, dan telekomunikasi 3,86\%. Kondisi ini membuat sejumlah pemilik media outdoor merugi cukup besar.

Strategi prioritas pertama yang harus dilakukan oleh PT. SUMO Advertising adalah strategi diversifikasi konsentris yaitu menciptakan produk iklan yang baru mengikuti perkembangan teknologi informasi seperti iklan LED, media sosial dan TV. Beberapa implikasi strategi yang perlu dilakukan adalah merubah arah perusahan dari media owner menjadi media agensi, melakukan komunikasi dengan semua SDM dan membuat perencanaan dalam menciptakan produk baru perusahaan, mengevaluasi titik iklan yang dimiliki agar terintegrasi dengan produk baru yang mobile dan mengikuti perkembangan e-commerce, joint Venture dengan partner yang sudah berpengalaman di iklan media LED, Media sosial dan TV dan menciptakan produk e-commerce bekerja sama dengan departemen pemerintah yang bertujuan untuk memajukan agribisnis di Indonesia.

\section{KESIMPULAN}

Kondisi internal PT. SUMO Advertising adalah memiliki kekuatan dalam hal kepercayaan klien juga budaya perusahaan yang kuat menghasilkan kapasitas perusahaan yang sebenarnya bisa terus bersaing di industri selain media luar ruang. Kondisi eksternal PT. Pariwara Advertising berupa ancaman yang paling kuat untuk perusahaan adalah regulasi pemerintah daerah DKI Jakarta. Di awal tahun 2019, dengan adanya Pergub No. 1 Tahun 2015 tentang Larangan Penyelenggaraan Reklame Rokok dan Produk Tembakau pada Media Luar Ruang menyebabkan lemahnya pertumbuhan industri media luar ruang Prioritas strategi yang harus dilakukan oleh PT. Pariwara Advertising adalah diversi @kasi konsentris, yaitu menciptakan produk iklan baru mengikuti perkembangan teknologi informasi seperti iklan LED, media sosial dan TV. Langkah konkrit yang dilakukan adalah dengan merubah fokus perusahaan dari media owner menjadi media agency sehingga pangsa pasar PT. Pariwara Advertising lebih luas.

\section{DAFTAR PUSTAKA}

Adhitya Wulanata Chrismastianto, I. (2017). Analisis Swot Implementasi Teknologi Finansial Terhadap Kualitas Layanan Perbankan Di Indonesia. Jurnal Ekonomi Dan Bisnis, 20(1), 133-144. Https://Core.Ac.Uk/Download/Pdf/190864220.Pdf

Dokman Marulitua Situmorang, Erlina, B. S. (2018). Pengaruh Kompetensi Dan Independensi Auditor Terhadap Kualitas Audit Dengan Etika Auditor Sebagai Variabel Moderating Pada Kantor Akuntan Publik Di Kota Medan. Jurnal Ilmiah Akuntansi Dan Finansial Indonesia, 2(1), 29-40.

Handayani, S. M., \& Nurlaila, I. (2017). Analisis Pemasaran Susu Segar Di Kabupaten Klaten. Sains Peternakan, 9(1), 41. Https://Doi.Org/10.20961/Sainspet.V9i1.4768

Hermawan, H. (2017). Pengembangan Destinasi Wisata Pada Tingkat Tapak Lahan Dengan

$\begin{array}{lllll}\text { Pendekatan Analisis } & \text { Swot. }\end{array}$

Https://Doi.Org/10.31219/Osf.Io/E783t

Munadi, F. A. (2008). Analisis Strategi Pemasaran Untuk Meningkatkan Penjualan Kendaraan Motor Pada Cv Turangga Mas Motor. Journal Of Economics, 1-14.

Noor, S. (2014). Penerapan Analisis Swot Dalam Menentukan Strategi Pemasaran Daihatsu Luxio Di Malang. Jurnal Intekna, 14(2), 102-209. 
Nugraha, S. A. S., Achmadi, F., \& Gustopo, D. (2016). Implementasi Strategi Line Extension Berdasarkan Marketing Mix Dan Analisa Swot Di Pt . Velesia ( Wisata Tas Rajut Kaboki ). Jurnal Teknologi Dan Manajemen Industri, 2(Swot), 23-28.

Putong, I. (2003). Teknik Pemanfaatan Analisis Swot Tanpa Skala Industri (A-Swot-Tsi). Jurnal Ekonomi \& Bisnis,

Http://Repository.Gunadarma.Ac.Id/Bitstream/123456789/491/1/Putong_65-71.Pdf

Tamara, A. (2016). Implementasi Analisis Swot Dalam Strategi Pemasaran Produk Mandiri Tabungan Bisnis. Jurnal Riset Bisnis Dan Manajemen, 4(3), 395-406. 